\title{
Medicina natural de la población ulwa de Karawala
}

Carmela Baptis

\section{INTRODUCCIÓN}

En la Desembocadura de Río Grande, la medicina natural y tradicional se integran armónicamente con la medicina convencional del sistema de salud nicaragüense, para resolver las necesidades de la población cuando ésta requiere de dicho servicio. El recopilar estos conocimientos del pueblo ulwa, por un lado fortalecerá las capacidades individuales y colectivas, áreas de la medicina natural y tradicional del pueblo ulwa, y por otro lado servirá como instrumento de rescate y revitalización cultural, particularmente para la promoción del patrimonio inmaterial del pueblo ulwa.

La cosmovisión ulwa permite valorizar la importancia de la creación natural y las capacidades de aquellos portadores que emplean técnicas y procedimientos para la promoción de salud, prevención de las enfermedades, tratamiento y rehabilitación, con sistemas médicos basados en métodos tradicionales.

Mediante entrevistas y la formación de grupos focales, la presente investigación recopila información sobre los diferentes médicos y medicinas tradicionales en la comunidad de Karawala. Esto aportaría a la elaboración de un recetario y a la creación de un listado de portadores culturales con dominio de información de las diferentes plantas medicinales y las enfermedades que éstas curan. También, la población conocerá dónde localizar a los médicos y cómo tratar sus enfermedades.

\section{IMPORTANCIA DE LA MEDICINA NATURAL EN LA COMUNIDAD DE KARAWALA}

Los portadores culturales consideran que la medicina tradicional es importante en la cultura del pueblo ulwa de Karawala, pues significa una herencia de sus antepasados y se puede obtener fácilmente dado que se encuentra en los patios de casi todos los hogares de la comunidad. Además, según la población, su efectividad es del 100\%, de tal manera que la mayor parte de los pobladores utilizan la medicina tradicional de forma cotidiana y sólo asisten a los centros de medicina clínica si la enfermedad es grave. Por otro lado tiene la ventaja de no contener químicos fuertes como la medicina moderna.

Los portadores culturales de mayor edad creen que la medicina tradicional ulwa sobrevivirá por muchos años, pero que los jóvenes tienen que jugar un papel muy importante para la herencia de este legado, pues son ellos quienes deben aprender de las plantas y animales y la preparación de las recetas, para que su uso no se pierda con el tiempo, debido a la modernización de la medicina clínica.

Respecto a las personas más jóvenes de la comunidad, la medicina tradicional está siendo transmitida de forma cotidiana en todos los hogares de familias ulwas; además, en la comunidad hay grupos de adultos que se reúnen con los jóvenes para darles charla sobre la importancia y beneficios de la medicina tradicional.

\section{INVENTARIO DE LAS PLANTAS MEDICINALES Y ENFERMEDADES}

El 100\% de los portadores culturales entrevistados conocen las plantas medicinales de la zona y la preparación de los remedios caseros que se utilizan en la comunidad. En total fueron mencionadas 18 plantas y 19 preparaciones caseras.

\section{Plantas}

Se logró inventariar 20 plantas medicinales: marañón, limón, zacate limón, el fruto de coco, hoja de hierba buena, hoja de naranja agria, hoja de sorrosi, fruta de toronja, cáscara de mango, hoja de eucalipto, raíz de cuculmeka, hoja de achiote, hoja de jícaro, hoja de guanábana, flores de mosquiteros, hoja de albahaca, palo de hombre grande, raíz del árbol de kowfot (pata de vaca). 


\section{Enfermedades}

Estas 20 plantas medicinales se utilizan para diferentes enfermedades; entre las afecciones más comunes tenemos 11:

1. Síntomas de diarrea (cáscara de palo de marañón).

2. Síntomas de tos (jugo de limón con miel de abeja).

3. Fiebres altas (hoja de zacate de limón).

4. Estreñimiento (leche de coco seco, en adultos y niños).

5. Síntomas de tos y calenturas (hoja de hierba buena).

6. Síntomas de presión alta (hojas de naranja agria y hoja de sorrosi).

7. Pacientes de hipertensión arterial (fruta de toronja).

8. Síntomas de diabetes (cáscara de mango con hoja de eucalipto).

9. Síntomas de diarreas con moco y sangre (cáscara del fruto de marañón).

10. Pacientes que presentan anemia (raíz de cuculmeka).

11. Síntomas de diarrea (coco tierno).

12. Gases estomacales (hoja de achiote).

13. Problemas de mareos y náuseas (hojas de jícaro).

14. Pacientes que desean tener suerte (hoja de guanábana y flores de mosquiteros).

15. Síntomas de calenturas y dolor de cabeza (hojas de albahaca).

16. Síntomas de reumatismo en las personas adultas (corteza de hombre grande).

17. Pacientes con diabetes (rama de árbol de hombre grande).

\section{RECETARIO DE PLANTAS MEDICINALES}

1. Cáscara de palo de marañón: se utiliza contra la diarrea.

\section{Preparación}

Se descascara una cantidad considerable de la corteza del árbol, unos tres pedazos, y se pone a hervir en un litro de agua.

\section{Dosificación}

Tomar dos cucharadas cada vez que se defeca, hasta que los síntomas de la diarrea ceden.
2. Jugo de limón con miel de abeja, para la tos.

Tres limones, una botella de miel de abeja.

\section{Preparación}

Se exprime el limón en la botella de miel de abeja y se mezcla.

\section{Dosificación}

Adultos: tomar una cucharada cada ocho horas.

Niños: tomar una cucharadita cada ocho horas.

3. Hoja de zacate limón: se utiliza en los síntomas de fiebre alta.

15 hojas del zacate limón cortadas desde la raíz.

\section{Preparación}

Hervir las hojas en un litro de agua.

\section{Dosificación}

Se toma una taza, más o menos tibia, cada ocho horas hasta que la fiebre cede.

4. Leche de coco seco, para los síntomas del estreñimiento en adultos y niños.

\section{Preparación}

Se pela el coco seco, se raya. Luego se exprime una sola vez la leche, y se bebe.

\section{Dosificación}

Se da al paciente una taza única de leche en ayuno.

5. Hoja de hierba buena para los síntomas de tos y calentura.

\section{Preparación}

Hervir 12 hojas de hierba buena con cuatro de culantro en $1 / 2$ litro de agua.

\section{Dosificación}

Se toma una cucharada cuatro veces al día hasta que los síntomas desaparezcan.

6. Hoja de naranja agria y hoja de sorrosi para los síntomas de presión alta

\section{Preparación}

Hervir 12 hojas de naranja agria y cinco de sorrosi, en un litro de agua. 


\section{Dosificación}

Se utiliza solo en pacientes adultos, se toma medio vaso cada ocho horas todos los días.

7. Jugo de fruta de toronja: se utiliza en pacientes de hipertensión arterial.

\section{Preparación}

Solo en pacientes adultos. Se exprime el jugo de tres frutas de toronjas y se almacena el jugo en un recipiente por un día.

\section{Dosificación}

Se calienta un poco el jugo de toronja antes de tomarlo. Se ingiere aproximadamente media taza de jugo. El tratamiento se repite cada ocho horas todos los días

8. Cáscara de mango con hoja de eucalipto y cáscara de aguacate, para la neumonía.

\section{Preparación}

Se hierve tres hojas de aguacate, tres pedazos de cáscara de mango y tres hojas de eucalipto, en un litro de agua.

\section{Dosificación}

Adultos: se toma tres cucharadas cada ocho horas.

Niños: 1 cucharadita cada ocho horas hasta curarse.

\section{Cáscara del fruto de marañón: se utiliza en pacientes} con síntomas de diarreas con moco y sangre.

\section{Preparación}

Utilizar 12 pedazos de cáscara de marañón, en dos litros de agua, se ponen a hervir las cáscaras de marañón hasta que el agua oscurezca.

\section{Dosificación}

Al enfriarse se toma un cuarto de vaso cada vez que se defeca, hasta curarse.

10. Raíz de cuculmeka: se utiliza con pacientes que presentan anemia.

\section{Preparación}

Se corta en pedazos una libra de cuculmeka, se lava bien y se hierve en tres litros de agua por 30 minutos, al enfriarse está lista para tomar.

\section{Dosificación}

Para adultos mayores se toma medio vaso con leche y azúcar al gusto cada 12 horas.

Para niños se toma un cuarto de vaso con leche, cada doce horas hasta curarse.

11. Coco tierno: se utiliza en los síntomas de diarrea.

\section{Preparación}

Se utilizan tres coquitos tiernos, se cortan en pequeños trozos y se ponen a hervir en un litro de agua. Se deja que hierva por media hora, luego se deja enfriar por otra media hora.

\section{Dosificación}

Adultos mayores: tres cucharadas cada ocho horas

Niños: tres cucharaditas cada ocho horas hasta curarse.

12. Hoja de achiote: se utiliza en pacientes que presentan síntomas de gases estomacales.

\section{Preparación}

Utilizar 20 hojas tiernas, lavarlas y ponerlas a hervir en un litro de agua, luesgo esperar a que enfríe.

\section{Dosificación}

Adultos: un cuarto de vaso cada ocho horas

Niños: una cucharadita cada ocho horas hasta curarse.

13. Hojas de jícaro y hierba buena: se utilizan en pacientes con problemas de mareos y náuseas.

\section{Preparación}

Catorce hojas de hierba buena, cuatro hojas de jícaro y se mezclan en un galón de agua.

\section{Dosificación}

Adultos: beber un vaso al día y mojar la cabeza con el mismo líquido por una semana.

14. Hoja de guanábanas y flores de mosquiterros: se utiliza en pacientes que desean tener suerte.

\section{Preparación}

Seis hojas de guanábana y flores de mosquitero se mezclan en un balde de agua 


\section{Dosificación}

\section{Para adultos solamente}

Se utiliza todo el balde con la mezcla, se baña al paciente los días viernes a las doce del mediodía, hasta adquirir buena suerte.

15. Hoja de albahaca y hojas de guanábanas, para pacientes con síntomas de calentura y dolor de cabeza.

\section{Preparación}

Se usan nueve hojas de albahaca y seis de guanábana, luego se machacan los dos tipos de hojas en un trapo limpio hasta que quede una consistencia fina, después se transfiere la mezcla a otro trapo limpio.

\section{Dosificación}

Al paciente se le ata un trapo con la mezcla en la frente por tres días, cada día se cambia el trapo por uno limpio con nueva mezcla.

16. Rama de hombre grande: para los síntomas del reumatismo en las personas adultas.

\section{Preparación}

Se corta la rama de hombre grande en pedazos pequeños, se utiliza cinco unidades de dos pulgadas, se dejan sumergidos en una botella de vino tinto grande (Cóndor).

Dosificación

Adultos: tomar tres cucharadas tres veces al día.

\section{PORTADORES CULTURALES QUE BRINDARON INFORMACIÓN}

Melencia William Crimens, Tomas William, Silvia Miller Conernelio, Leonel Alonso Albares, Modesta

Gómez, Esmelda Cornelios, Morfin Salazar, Hedly Rodriguez, Sara Katral Crimens

\section{REFERENCIAS BIBLIOGRÁFICAS}

Altamirano M. Floripe. F. A. (1998). "Médicos del pueblo”. CECALLI, Año 2, \# 5. Estelí, Nicaragua.

UNESCO (2009). Diagnostico Sociocultural de la costa Caribe de Nicaragua.

UNESCO (1982): Declaración de México.

Brüssel (2002). Salud en sus manos. Manual sobre el uso de las plantas medicinales. Fundación Centro Nacional de Medicina Popular Tradicional. 1ª Edición, Estelí, Nicaragua.

Carraza (2000). Condimentos, hierbas y especies. Managua, Nicaragua.

Hernandez A. Jorge Nicaragua. (1999) Programa nacional de medicina tradicional y natural, Ministerio de salud público. 